\title{
Viable microbial community composition of Agnano Thermal Spring Water
}

\author{
Sara Cacciapuoti ${ }^{1}$, maria antonietta luciano ${ }^{2}$, Roberta Colicchio ${ }^{3}$, Chiara Pagliuca ${ }^{3}$, \\ Giuseppe Mantova ${ }^{3}$, Paola Salvatore ${ }^{3}$, and Gabriella Fabbrocini ${ }^{3}$ \\ ${ }^{1}$ University of Naples Federico II \\ ${ }^{2}$ Università degli Studi di Napoli Federico II \\ ${ }^{3}$ Affiliation not available
}

August 17, 2020

\begin{abstract}
The Agnano thermal spring water (ATSW) is mainly a salso-bromo-iodic-bicarbonate-alkaline-sulphurous water. Since ancient time, the benefits of thermal spring water in the treatment of various diseases have been known. Today it is known that thermal spring water acts effectively on various physiological and pathological processes such as skin regeneration, respiratory and cardiovascular diseases and bone illnesses and most of these beneficial effects depend on the chemical and physical properties of water. However, all the benefits of thermal spring water may not be fully explained only by its mineral composition. In this regard, it is known that non-pathogenic bacterial populations play an active role in various processes in the ecological and biological fields. The aim of the present study is the microbiological characterization of ATSW through the use of two distinct methods in order to determine the total viable bacterial community.
\end{abstract}

\section{Introduction}

The Agnano thermal spring water (ATSW), located in the largest thermal basin in Italy with its 72 springs of various nature and characteristics, have been the best expression of this for millennia. Already in the first century. a.C., the Hellenists understood its high curative value, both physical and spiritual, later in the second century. d.C. the Romans began to build structures for the exploitation of these portentous waters. Indeed, with the allocation of the Romans in Flegrea Area began the real thermal activity across the Campi Flegrei. The impressive thermal spa of the Hadrian era (117-138 d.C.) which stands on the south-western side of the Agnano basin, on the slopes of Monte Spina, testifies that thermalism was widespread in Agnano. The benefits of thermal spring water in the treatment of various diseases have been known since ancient times. In fact, thermal spring water has therapeutic functions and can be used in the treatment of various dysfunctions, from respiratory and rheumatic diseases to gynecological and gastrointestinal diseases. Today it is known that thermal spring water acts effectively on various physiological and pathological processes such as: skin regeneration (Liang et al., 2015), cardiovascular diseases (Oyama et al., 2013) and bone diseases (Fioravanti et al., 2011) and most of these beneficial effects depend on the chemical and physical properties of water.

However, all the benefits of thermal spring water, such as improved migration and cell proliferation or antiinflammatory and regenerative properties, may not be fully explained only by its mineral composition. In this regard, it is known that non-pathogenic bacterial populations play an active role in various processes in the ecological and biological fields (Nicoletti et al., 2015; Zeichner et al., 2018). Maintaining the physiological intestinal well-being is a clear example of how a bacterial microflora is essential for regulating homeostasis, metabolic functions and the immunological response (Sommer et al., 2017). 
Sulfurous waters are the most numerous in Italy and the presence of $\mathrm{H}_{2} \mathrm{~S}$ influences immunological response (Valitutti et al., 1990) and have beneficial effects on neurodegenerative disorders, respiratory tract (Keller et al., 2014) and in particular on cardiac functions, as also carbonic waters.

Agnano's thermal baths belong to the largest volcanic area of the Mediterranean Sea (ca $400 \mathrm{Kmq})$. It is the only example of thermal spring water extended in urbane area with a huge impact landscape and a great archeological significance. The Agnano thermal spring water (ATSW) is mainly a salso-bromo-iodicbicarbonate-alkaline-sulphurous water. Thanks to the variability of the temperature and the abundance of mineral elements (sodium chloride, iodine, bromine, calcium, bicarbonate, sulphides), a great number of different disorders can be treated (cardiovascular, gynecological, dermatological and rheumatic).

The aim of the present study is the microbiological characterization of ATSW through the use of two distinct methods in order to determine the total viable bacterial community.

\section{Material and Methods}

\section{ATSW collection}

ATSW was collected in two different seasons of the year; in winter (January 2019) and in autumn (October 2019) with an aseptic procedure. Using surgical gloves, $3000 \mathrm{ml}$ of water was collected with a sterile $50 \mathrm{ml}$ syringe, close to the thermal spring. The samples were poured into three $1 \mathrm{~L}$ containers for microbiological analysis (VWR) and transported as soon as possible for microbiological analysis and processed rapidly following collection. The in situ temperature of water, in winter's sampling, was $55.4{ }^{\circ} \mathrm{C}$ and in situ $\mathrm{pH}$ was 6.8 - 7 whereas, in autumn's sampling, the temperature was $56{ }^{\circ} \mathrm{C}$ and $\mathrm{pH}$ was still $6.8-7$. Chemical composition of ATSW was reported inTable 1 .

\section{Microbiological analysis}

\section{Filtration procedure and isolation of bacteria}

A portion of $100 \mathrm{ml}$ of ATSW was filtered through seven $0.20 \mu \mathrm{m}$ pore cellulose nitrate membranes (Nalgene 0.2 Analytical Filter Unit; Thermo Fisher Scientific, Inc., Waltham, MA, USA). Each membrane was plated on differential and selective media (Tryptic Soy Agar Blood BD, Chocolate agar BD, McConkey agar Oxoid, Mannitol Salt agar Oxoid, Sabouraud dextrose agar Oxoid, Colistin Nalidixic acid agar Biolife, Schaedler agar $\mathrm{BD}$ ) incubated in aerobic condition at $37^{\circ} \mathrm{C}$ for $2-3$ days and in anaerobic condition at $37^{\circ} \mathrm{C}$ for 3 days. For autumn sampling, the bacterial plates were also incubated at $55{ }^{\circ} \mathrm{C}$ in order to mimic the temperature of thermal water. Microbial growth was then recorded and each pure culture was subsequently prepared and stored at $-80^{\circ} \mathrm{C}$. At the same times, $300 \mathrm{ml}$ of water sample was filtered through $0.20 \mu \mathrm{m}$ pore cellulose nitrate membrane and the filter was soaked in $5 \mathrm{ml}$ of $1 \mathrm{X}$ phosphate-buffered saline (PBS, containing $140 \mathrm{mM}$ $\mathrm{NaCl}, 2.7 \mathrm{mM} \mathrm{KCl}, 10 \mathrm{mM} \mathrm{Na}_{2} \mathrm{HPO}_{4}, 18 \mathrm{mM} \mathrm{KH}_{2} \mathrm{PO}_{4}, \mathrm{pH}$ 7.4) in a centrifugal tube (Di Natale et al., 2018). Vortexing was performed for 2-3 min with a vortex touch mixer (HeidolphREAX 2000) to evaluate the presence ofLegionella pneumophila antigen (ALERE BINAXNOW@ Legionella antigen card) following the instructions of the manufacturer.

\section{Enrichment procedure and isolation of bacteria}

ATSW sample $(10 \mathrm{ml})$ was transferred to nutrient Brain Hearth Infusion broth $(90 \mathrm{ml})$ (Oxoid, Thermo Fisher Scientific, Inc., Waltham, MA, USA). The sample was incubated at $37^{\circ} \mathrm{C}$ with $220 \mathrm{rpm}$ until turbidity was been detectable. For autumn sampling, the bacterial inocula were also incubated at $55{ }^{\circ} \mathrm{C}$ with $220 \mathrm{rpm}$. After the appropriate incubation, the broth culture was centrifugated at $3500 \mathrm{rpm}$ for $10^{\prime}$ at room temperature, and serial dilutions were plated on differential and selective media as mentioned above. Separated colonies were then obtained by streaking on selective agar media for several times.

\section{Identification of bacterial isolates}

The identification of all bacterial isolates was performed by mass spectrometry using the Matrix Assisted Laser Desorption/Ionization (MALDI) mass spectrometer (Bruker Daltonics, MALDI Biotyper, Fremont, 
CA, USA), a high-throughput proteomic technique for identification of a variety of bacterial and fungal species (Sogawa K. et. al, 2011; Ferrazzano G.F. et. al, 2017; Cicatiello A.G. et al, 2014). Through this identification procedure a reliability threshold of 1.4 was established.

\section{Results and Discussion}

Microbiological analyses for the two collections of ATSW, "Nuove Terme di Agnano srl", was performed during the winter and autumn seasons through two procedures, in order to increase the yield for the microbiological characterization. The two procedures, filtration and enrichment, highlighted in both sampling the abundance of bacterial species belonging mainly to three different phyla: Actinobacteria, Firmicutes and Proteobacteria with a prevalence of species belonging to the phylum Firmicutes (Table 2). The filtration procedure determined the isolation of four bacterial isolates for winter sampling and ten isolates form autumn sampling, while the enrichment method revealed the presence in thermal water of sixteen different bacterial species for winter sampling and eight bacterial species for autumn sampling (Table 3). The analysis showed a difference between the bacterial populations associated with seasonal changes, highlighting a majority of species belonging to the genus Staphylococcus, with a prevalence of Coagulase-negative Staphylococci (ConS) for winter sampling using enrichment procedure, and the genus Bacillus for autumn sampling, using both procedures. To underline, the species Pseudomonas stutzeri and Bacillus subtilis have been isolated from cultures incubated at $50^{\circ} \mathrm{C}$ for autumn sampling.

The most represented phylum, Firmicutes, mainly includes gram-positive species with a genome characterized by a low GC content and includes several mobile and capable of forming endospores species (Schleifer, 2009). The members of this phylum are abundant in soil and water where they are involved in the decomposition and recycling of organic matter (Gibbons and Murray, 1978). However, different genera of phylum Firmicutes belong to the normal human flora or can be associated with diseases in humans and animals (Baik et al., 2008). Moreover, some members of this phylum may have an industrial use for the production of enzymes or antimicrobial and antifungal activities, such as the speciesLactobacillus plantarum, which is used in the food industry, andBacillus pumilus, which has an antimicrobial activity towards Vibrio spp. and fungicide (Liu et al., 2012) (both isolated during the autumn sampling by filtration procedure).

Within the phylum Proteobacteria, in particular, in the Gamma proteobacteria some Pseudomonas spp. like $P$. luteola and P. stutzeri, could be relevant because they are both involved in bio-absorption's mechanisms. P. luteola is involved in bio-absorption processes of heavy metals such as chromium and aluminum in acid environments, metal ions often present in industrial waste water and is also involved in the absorption of copper and nickel as it is a producer of exopolysaccharide (Ozdemir and Baysal, 2004). Also, the species P. stutzeri is considered an excellent candidate for the simultaneous absorption of nitrogen and phosphate in waste water, in fact it oxidizes ammonia exhibiting the ability of nitrification and denitrification as well as the ability to degrade organophosphorus pesticides (Ozdemir et al., 2005).

Among the identified phyla is represented, although to a lesser extent, the phylum Actinobacteria. To this phylum belong different genera of Gram positive bacteria present both in terrestrial and aquatic environments. These microorganisms have a great importance for the human being since agriculture and forests depend on the contribution of these bacteria to the processes that take place in the soil. In this environment, the Actinobacteria grow with characteristics similar to fungi, forming extensive structures similar to mycelia, favoring the decomposition of the organic matter of dead organisms so as to provide the essential elements for plant growth (Servin et al., 2008).

Therefore, the ATSW analyzed is rich in non-pathogenic bacteria that may play a role in treating various skin disease (Balato et al., 2019). As ATSW contains live bacteria that could impact the skin's microbiota, the water itself is considered to be a probiotic (Zeichner et al., 2018). Although probiotics have been widely used in the past for the treatment/prevention of gastrointestinal disorders, a growing number of evidences has suggested that they can modulate the composition of microbial community, exerting their healthy effect directly or indirectly on the skin (Balato et al., 2019; Zeichner et al., 2018).

Moreover, the ATSW is a rich source of minerals. About 31 minerals have been identified of which 17 are 
found as major ions $(>/=0,4 \mathrm{mg} / \mathrm{l})$ like chloride, sodium, bicarbonate, sulphate, carbon dioxide, potassium, silicon, calcium, magnesium, boron, ammonium, bromide, strontium, litium, fluoride, manganese, arsenic.

Sodium helps to maintain the suppleness of skin due to its water-holding capacity. Hence it is very useful in dry dermatoses like psoriasis and ichthyosis. It also helps in desquamation of hyperkeratotic lesions (Rivaz et al., 2011).

Noteworty, among cations of interest, $\mathrm{Mg}^{2+}$ and $\mathrm{Ca}^{2+}$ have been recognized for their benefits in skin barrier recovery (Denda et a., 1999). In normal skin, magnesium and calcium ions were localized with a high concentration in the upper epidermis (Proksch et al., 2005). After barrier disruption, the gradients of calcium, magnesium, and potassium in the epidermis disappeared while the $\mathrm{pH}$ was not altered (Denda et a., 1999). Loss in the ion gradient is a signal for an increase in proliferation, differentiation and lipid synthesis aimed to repair the perturbed barrier (Lee et al., 1992, Denda et al., 2003). Magnesium is also essential for cell metabolism. It helps in maturation and differentiation of keratinocytes. Hence it is very useful in psoriatic patients who have a low magnesium level in the serum and scales (Rivaz et al., 2011). Calcium-and magnesium-rich thermal spring waters are known to improve skin barrier function and accelerate wound healing (Proksch et al., 2005).

Moreover, the soothing and protective properties of thermal spring waters in sensitive skin (antioxidant or anti-ageing) are enhanced by the presence of trace elements such as selenium, strontium (Celerier et al., 1995). These properties have been demonstrated in many studies using human keratinocytes, fibroblasts or other response-appropriate cell lines (Seite et al., 2013; Joly et al., 1998). Furthermore, a recent study demonstrated the activity of salso-bromo-iodine water on mucous-secretory disorders, in particular it helped to improve the relationship between the mucous-protein complexes and the water: initially, this action was congestive, subsequently, it became an anti-catarrhal, anti-inflammatory, antiseptic and immunostimulant action (La Mantia et al., 2018).

The ATWS for its mineral composition and microbial diversity exhibits both prebiotic and probiotic characteristic, thus it will be analyzed for its anti-inflammatory and regenerative properties in an in vitro system.

\section{References}

1. Baik KS, Park SC, Kim EM, Bae KS, Ahn JH, KaJ O, Chun J, Seong CN. Diversity of bacterial community in freshwater of Woopo wetland. J Microbiol. 2008 Dec;46(6):647-55.

2. Bergey's Manual of Systematic Bacteriology, volume 3: The Firmicutes. Editors: Vos, P., Garrity, G., Jones, D., Krieg, N.R., Ludwig, W., Rainey, F.A., Schleifer, K.-H., Whitman, W. 2009

3. Cicatiello AG, Iula DV, Pagliuca C, Pastore G, Pagliarulo C, Catania MR, Colicchio R, Picardi M, Raia V, Salvatore P. Identification ofInquilinus limosus in cystic fibrosis: a first report in Italy. New Microbiol. 2014 Oct;37(4):567-71.

4. Di Natale, F., Manna, L., La Motta, F., Colicchio, R., Scaglione, E., Pagliuca, C., Salvatore, P. Capture of bacterialbioaerosol with a wetelectrostaticscrubber. Journal of Electrostatics. Volume 93, June 2018, Pages 58-68.

5. Ferrazzano GF, Scioscia E, Sateriale D, Pastore G, Colicchio R, Pagliuca C, Cantile T, Alcidi B, Coda M, Ingenito A, Scaglione E, Cicatiello AG, Volpe MG, Di Stasio M, Salvatore P, Pagliarulo C. In Vitro Antibacterial Activity of Pomegranate Juice and Peel Extracts on Cariogenic Bacteria. Biomed Res Int. 2017; 2017: 2152749.

6. Fioravanti A, Cantarini L, Guidelli GM, Galeazzi M. Mechanisms of action of spa therapies in rheumatic diseases: what scientific evidence is there? Rheumatol Int. 2011 Jan;31(1):1-8.

7. Gibbons, N. E. \& Murray, R. G. E. 1978. Proposals concerning the higher taxa of bacteria. Int $J$ SystBacteriol 28:1-6.

8. Keller S, König V, Mösges R. Thermal water applications in the treatment of upper respiratory tract diseases: a systematic review and meta-analysis. J Allergy (Cairo). 2014;2014:943824.

9. Liang J, Kang D, Wang Y, Yu Y, Fan J, Takashi E. Carbonate ion-enriched hot spring water promotes skin wound healing in nude rats. PLoS One. 2015 Feb 11;10(2):e0117106. 
10. Liu Y, Zuo S, Xu L, Zou Y, Song W. Study on diversity of endophytic bacterial communities in seeds of hybrid maize and their parental lines. Arch Microbiol.2012 Dec;194(12):1001-12. doi: 10.1007/s00203012-0836-8. Epub 2012 Aug 15.

11. Nicoletti G, Corbella M, Jaber O, Marone P, Scevola D, Faga A. Non-pathogenic microflora of a spring water with regenerative properties. Biomed Rep. 2015 Nov;3(6):758-762.

12. Zeichner J, Seite S. From Probiotic to Prebiotic Using Thermal Spring Water. J Drugs Dermatol. 2018 Jun 1;17(6):657-662. Review.

13. Oyama J, Kudo Y, Maeda T, Node K, Makino N. Hyperthermia by bathing in a hot spring improves cardiovascular functions and reduces the production of inflammatory cytokines in patients with chronic heart failure. Heart Vessels.

14. Ozdemir G, Baysal SH. Chromium and aluminum biosorption on Chryseomonasluteola TEM05. ApplMicrobiolBiotechnol. 2004 May; 64(4):599-603.

15. Ozdemir G, Ceyhan N, Manav E. Utilization of an exopolysaccharide produced by ChryseomonasluteolaTEM05 in alginate beads for adsorption of cadmium and cobalt ions. Bioresour Technol. 2005 Oct;96(15):1677-82.

16. Servin JA, Herbold CW, Skophammer RG, Lake JA. Evidence excluding the root of the tree of life from the actinobacteria. MolBiolEvol. 2008 Jan;25(1):1-4.

17. Balato A, Cacciapuoti S, Di Caprio R, Marasca C, Masarà A, Raimondo A, Fabbrocini G. Human Microbiome: Composition and Role in Inflammatory Skin Diseases. Arch Immunol Ther Exp (Warsz). 2019 Feb;67(1):1-18.

18. Sogawa K., Watanabe M., Sato K. Use of the MALDI BioTyper system with MALDI-TOF mass spectrometry for rapid identification of microorganisms. Analytical and Bioanalytical Chemistry. 2011;400(7):1905-1911.

19. Sommer F, Anderson JM, Bharti R, Raes J, Rosenstiel P. The resilience of the intestinal microbiota influences health and disease. Nat Rev Microbiol. 2017 Oct;15(10):630-638.

20. Valitutti S, Castellino F, Musiani P. Effect of sulfurous (thermal) water on T lymphocyte proliferative response. Ann Allergy. 1990 Dec;65(6):463-8.

21. Riyaz N, Arakkal FR. Spa therapy in dermatology. Indian J Dermatol Venereol Leprol. 2011 MarApr;77(2):128-34.

22. Denda M, Katagiri C, Hirao T, Maruyama N, Takahashi M. Some magnesium salts and a mixture of magnesium and calcium salts accelerate skin barrier recovery. Arch Dermatol Res. 1999 Oct;291(10):560-3.

23. Proksch E, Nissen HP, Bremgartner M, Urquhart C. Bathing in a magnesium-rich Dead Sea salt solution improves skin barrier function, enhances skin hydration, and reduces inflammation in atopic dry skin. Int J Dermatol. 2005 Feb;44(2):151-7.

24. Lee SH, Elias PM, Proksch E, et al. Calcium and potassium are important regulators of barrier homeostasis in murine epidermis. J Clin Invest 1992; 89: 530-538.

25. Denda M, Fuziwara S, Inoue K. Influx of calcium and chloride ions into epidermal keratinocytes regulates exocytosis of epidermal lamellar bodies and skin permeability barrier homeostasis. J Invest Dermatol. 2003;121(2):362-367.

26. Celerier P, Richard A, Litoux P, Dreno B. Modulatory effects of selenium and strontium salts on keratinocyte-derived inflammatory cytokines. Arch Dermatol Res. 1995;287(7):680-2.

27. Seite S. Thermal waters as cosmeceuticals: La Roche-Posay thermal spring water example. Clin Cosmet Investig Dermatol. 2013;6:23-8.

28. Joly F, Charveron M, Ariès MF, Bidault J, Kahhak L, Beauvais F, Gall Y. Effect of Avène spring water on the activation of rat mast cell by substance P or antigen. Skin Pharmacol Appl Skin Physiol. 1998 Mar-Apr;11(2):111-6.

29. La Mantia I, Andaloro C. Effects of salso-bromo-iodine thermal water in children suffering from otitis media with effusion: a randomized controlled pilot study. Clin Ter. 2018 Jan-Feb;169(1):e10-e13.

\section{Hosted file}

table1.docx available at https://authorea.com/users/351071/articles/475749-viable-microbial- 
community-composition-of-agnano-thermal-spring-water

\section{Hosted file}

table2.docx available at https://authorea.com/users/351071/articles/475749-viable-microbialcommunity-composition-of-agnano-thermal-spring-water

\section{Hosted file}

table3.docx available at https://authorea.com/users/351071/articles/475749-viable-microbialcommunity-composition-of-agnano-thermal-spring-water 